investigation of these patients, incorporating both clinical and laboratory evidence. ${ }^{3}$ It would be of great value to carry out a skeletal muscle biopsy on the patient described by $\mathrm{Dr}$ Albin, looking for histochemical and biochemical evidence of mitochondrial respiratory chain dysfunction. These investigations are often abnormal in patients with neurological abnormalities resulting from mtDNA disease, and the characteristic mosaic pattern of cytochrome c oxidase activity in muscle or a biochemical complex deficiency may provide clues as to the nature of the underlying genetic defect. It is often difficult to ascribe pathogenicity to a mtDNA mutation, particularly if the disease has an unusual phenotype." "Therefore, although the clinical evidence presented by Dr Albin is compatible with a mitochondrial disorder, the inference that the $\mathrm{T} 4216 \mathrm{C}$ and G15257A nucleotide transitions are the primary aetiological factor responsible for Fuch's corneal dystrophy is unfounded.

PFC is a Wellcome Trust Research Fellow. RA is a MRC (UK) Research Fellow. NH is supported by the Wellcome Trust, The National Eye Institute (RO1 EY10758), and the John Sealy Memorial Endowment Fund.

PATRICK F CHINNERY DOUGLASS M TURNBULL Department of Neurology, The University of Newcastle upon Tyne, Newcastle upon Tyne NE2 4HH, UK NEIL HOWELL

Department of Radiation Oncology, University of Texas Medical Branch, Galveston, USA RICHARD M ANDREWS Department of Ophthalmology, The University of Newcastle upon Tyne, UK

1 Albin RL. Fuch's corneal dystrophy in a patient with mitochondrial DNA mutations. $\mathcal{f} \mathrm{Med}$ Genet 1998;35:258-9.

2 Chinnery PF, Turnbull DM. Mitochondrial medicine. $Q f$ Med 1997;90:657-66.

3 Chinnery PF, Turnbull DM. The clinical features, investigation and management of patients with mitochondrial DNA defects. $\mathcal{F}$ peurol Neurosurg Psychiatry 1997;63:559-63.

4 Howell N. Leber hereditary optic neuropathy: how do mitochondrial DNA mutations cause how do mitochondrial DNA mutations cause degeneration of the optic
Biomemb 1997;29:165-73.

5 McCartney MD, Robertson DP, Wood TO,

McCartney MD, Robertson DP, Wood TO, McLaughlin BJ. ATPase pump site density in human dysfunctional corneal epithelium

Ophthalmol Vis Sci 1987;28:1955-62.
6 Johns DR. The other genome: mitochondrial Johns DR. The other genome: mitochond
DNA and disease. Nat Med 1996;2:1065-8

7 Pineros O, Cohen EJ, Rapuano CJ, Laibson PR Long-term results after penetrating keratoplasty for Fuchs' endothelial dystrophy. Arch Ophthalmol 1996;114:15-18.

8 Howell N, Kubacka I, Halvorson S, Howell B, McCullough DA, Mackey D. Phylogenetic analysis of the mitochondrial genomes from analy Genetics 1995;140:285-302.

9 Torroni A, Petrozzi M, D'Urbano L, et al. Haplotype and phylogenetic analyses suggest that one European-specific mtDNA background one European-specific mtDNA background
plays a role in the expression of Leber plays a role in the expression of Leber hereditary optic neuropathy by increasing the and 14484. Am $\mathcal{f}$ Hum Genet 1997;60:1 107-21. 10 Howell N. Primary LHON mutations: trying to separate "fruy"

11 Schon EA, Bonilla E, DiMauro S. Mitochondrial DNA mutations and pathogenesis. $f$ Bioenerget Biomemb 1997;29:131-49.

\section{"Cataplexy" in Coffin-Lowry syndrome}

Crow et $a l^{1}$ reported an unusual, nonepileptic, cataplexy-like phenomenon in three males with Coffin-Lowry syndrome (CLS). The authors also provided evidence of neuromuscular dysfunction as part of the phenotype by showing abnormalities on muscle ultrasound in four gene carriers, and they commented on our observation of marked distal muscle wasting in two affected brothers, aged 15 and 14 years at the time of our report. ${ }^{2}$ In that report, we described the frequent occurrence of generalised epileptic seizures without pathognomonic epileptic elements on EEG after the age of 6 years. We had occasion to follow these CLS brothers up to their sudden death at the age of 32 and 34 years, respectively. During this follow up it became evident that the "epileptic episodes" were episodes of sudden, non-epileptic collapses with atonia; as in case 1 reported by Crow et al,' these episodes were precipitated by a loud noise or excitement. The frequency and severity of these drop attacks worsened with age and was correlated with a further progression of the peripheral muscle wasting and of a severe thoracolumbar torsion scoliosis, which finally resulted in acute cardiorespiratory failure.

Over the last 25 years we have had the opportunity to examine 20 other CLS males. In one of these patients the same type of sudden, non-epileptic attacks were noted from the age of 4 years. When walking this CLS boy suddenly dropped, always in a forward position, hurting himself. No epileptic discharges have ever been noted on repeated 24 hour EEG monitoring. Also, a progressive thoracolumbar scoliosis was noted in this boy, and after the experience in the two brothers we decided to operate on the scoliosis at the age of 14 years with satisfactory correction and stabilisation of the curvature. On that occasion a muscle biopsy was performed with normal results. Much to our surprise, the frequent episodes of sudden and reversible loss of muscle tone have completely disappeared after the scoliosis fusion.

In conclusion, our experience in CLS males confirms that "cataplexy" is not rare in this XLMR syndrome, as we observed it in three of 22 male patients. The aetiology and pathogenesis of this sudden collapse phenomenon remains unclear. In this perspective, it is of interest to note that these cataplexy-like symptoms increased in frequency and severity in the two brothers, together with progression of the torsion scoliosis and muscle wasting. In contrast, the collapse symptoms disappeared completely in the third male after surgical correction of the scoliosis.

\section{JEAN-PIERRE FRYNS} ERIC SMEETS

Centre for Human Genetics, University of Leuven, Herestraat 49, B-3000 Leuven, Belgium

1 Crow YJ, Zuberi SM, McWilliam R, et al. "Cataplexy" and muscle ultrasound abnormalities in Coffin-Lowry syndrome. $f \mathrm{Med}$ Genet 1998;35:94-8.

2 Fryns JP, Vinken L, Van den Berghe $H$. The Coffin syndrome. Hum Genet 1977;36:271-6.

\section{Autoclaving Guthrie cards does not prevent their use in PCR reactions!}

Doctors Rahman, Emery, and Poulton $(\mathcal{F}$ Med Genet 1998;35:263) point out their problems in obtaining neonatal screening dried blood spots or Guthrie cards from patients with the MELAS 3243 mutation. They comment that of the four cards they were able to obtain, one had been autoclaved. This, they claim, destroys the DNA.

Dried blood spot cards are commonly autoclaved or steamed before performing the bacterial inhibition assay for phenylalanine in screening for phenylketonuria (PKU). 'We have used such blood spots for analysis of the common mutations for medium chain acyl CoA dehydrogenase deficiency (MCADD), hereditary fructose intolerance, and the NARP 8993 mutation. One has also been successfully used for identification purposes by DNA fingerprinting. In a study of autoclaved blood spots from 5014 neonates in the West Midlands Region ${ }^{2}$ for the common MCADD mutation, a failure rate of PCR of only $0.3 \%$ was obtained.

Hence there is no reason to believe autoclaving per se substantially contributes to a poor PCR. In fact it may be that denaturing contaminating protein by autoclaving may help to reduce the amount of protein carried over during extraction and hence reduce the risk of PCR failure. However, we fully support the authors' suggestions for central funding for the storage of this important medical resource.

R G F GRAY $S$ K HALL

West Midlands Regional Laboratory for Neonatal Screening and Inherited Metabolic Disorders, The Birmingham Children's Hospital NHS Trust, Ladywood Middleway, Ladywood, Birmingham B16 8ET, UK

1 Guthrie R, Susi A. A simple method for detecting phenylketonuria in large populations newborn infants. Pediatrics 1963;32:334-8.

2 Seddon HR, Green A, Gray RFG, et al. Regional variations in medium chain acyl COA dehydrogenase deficiency. Lancet 1995;345: 135-6.

3 Seddon HR, Gray G, Pollitt RJ, et al. Population screening for the common G985 mutation causing medium chain acyl-COA dehydrogenase deficiency with Eu-labeled olignonucleotides and the DELFIA sytem. Clin Chem 1997;43:436-42.

\section{BOOK REVIEWS}

If you wish to order or require further information regarding the titles reviewed here, please write to or telephone the BMJ Bookshop, PO Box 295, London WC1H 9JR. Tel 01713836244 . Fax 01713836662. Books are supplied post free in the UK and for BFPO addresses. Overseas customers should add $15 \%$ for postage and packing. Payment can be made by cheque in sterling drawn on a UK bank or by credit card (Mastercard, Visa, or American Express) stating card number, expiry date, and full name. (The price and availability are occasionally subject to revision by the Publishers.)

Genetic Disorders and Pregnancy Outcome. Editors L D Platt, R Koch, F de la Cruz. (£55.00, \$98.00.) London: Parthenon Publishing. 1997. ISBN 1-85070-721-9.

Many clinicians who deal with high risk obstetrics or have specialised in maternalfetal medicine, obstetric physicians, and geneticists will welcome a book on the approach to management of people with genetic disorders who intend to have 